\title{
Metastatic ocular deposits due to bronchial carcinoma
}

\author{
C. C. EVANS, A. J. MEARNS, J. DELANEY, and W. A. LITTLER \\ Regional Cardiothoracic Surgical Centre, Broadgreen Hospital, Liverpool and Liverpool Royal Infirmary
}

Three case reports of patients with bronchial carcinoma who presented with visual disturbances due to ocular metastases are described. The reasons for the rarity of this syndrome are discussed and its frequent association with cerebral metastases is explained. Cytotoxic drugs provide shortterm effective therapy.

Bronchial carcinoma is an uncommon cause of secondary neoplasms affecting the eye. The first description of ocular metastases was by Perls in 1872 of a patient with a choroidal deposit and multiple cerebral metastases secondary to a primary carcinoma of the lung. Thomas, Algan, and Reny (1964) were able to find only two descriptions between 1890 and 1935 but, more recently, single case reports have included those of Haft and Worken (1954), De Ocampo and Espiritu (1959), Fishof (1960), Wright and Meger (1962), Koenig, Johnson, and Monahan (1963), and Sakula (1968).

This report describes three patients presenting with ocular metastases who were subsequently found to have a primary bronchial neoplasm.

\section{CASE REPORTS}

CASE 1 A 45-year-old man, who smoked 20 cigarettes each day, presented in April 1969 to St. Paul's Eye Hospital, Liverpool, with conjunctivitis for which no specific cause was found. Retinal examination was normal, but six months later he lost the vision of the left eye due to a detachment of the lower half of the left retina. Perimetry demonstrated complete loss of the upper half of the left visual field and infrared photography of both orbits showed increased activity on the left side. Further clinical examination revealed enlarged hard lymph nodes in both sides of the neck but the chest was clinically clear. A chest radiograph showed a mass in the left mediastinum and tomography confirmed a mass at the level of the aortic arch.

Bronchoscopy was normal but biopsy of a cervical lymph node showed a clear cell carcinoma of bronchial origin. It was decided to treat the patient with cyclophosphamide, $200 \mathrm{mg}$ intravenously daily for $\mathbf{1 0}$ days and subsequently $50 \mathrm{mg}$ three times a day orally. After three months' therapy, the scotoma had lessened, fundal appearances were improved, and infrared photography showed no difference in activity between the two sides.

Improvement was maintained until seven months $\overrightarrow{0}$ after the start of treatment when the patient developed $\perp$ dysphagia and dysarthria due to right-sided lower. cranial nerve palsies. He then deteriorated rapidly and died eight months after first presenting with visual loss.

Necropsy revealed multiple neoplastic masses in both lungs, extensive hilar and mediastinal lymph node $\mathbb{Q}$ deposits, and smaller lesions in the vault and base of $\Rightarrow$ the skull. Vertical section through the left eye (Figs 1 을 and 2) showed the secondary deposit.

CASE 2 A 54-year-old thermal insulator with 30 years' exposure to asbestos, who smoked 20 cigarettes each day, presented in January 1970 with loss of 은 vision in the right eye of sudden onset. He also com- $\tilde{x}$ plained of right supraorbital headache. Retinoscopy showed a flat grey choroidal tumour with haemorrhages and a secondary retinal detachment. Inspiratory crepitations were heard at the lung bases. A chest $₹$ radiograph revealed a rounded mass in the left lowero lobe and extensive fibrotic changes in both lung fields. As the patient was in considerable pain, unrelieved by analgesics, the right eye was enucleated. Histological examination revealed a choroidal deposit compatible $N$ with a secondary squamous carcinoma from the lung.

The patient was transferred to the Regional Cardio- $N$ thoracic Centre where the diagnosis of a primary bronchial carcinoma and pulmonary fibrosis due too asbestosis was confirmed. Many asbestos bodies were found in the sputum, and pulmonary function studies? revealed a restrictive pattern with slight reduction of the transfer factor. Vital capacity $2 \cdot 8 \mathrm{l}$., forced expira-tory volume $(1 \mathrm{sec}) 1.95 \mathrm{l}$. Transfer factor $70 \%$ of predicted normal.

Since the patient was free of symptoms after removal of the eye, no treatment was given, but in $\mathbb{\Omega}_{2}$ March he developed a motor dysphasia with papil-o loedema on the left side. Treatment with cyclophosphamide, $200 \mathrm{mg}$ intravenously daily, and dexametha- 


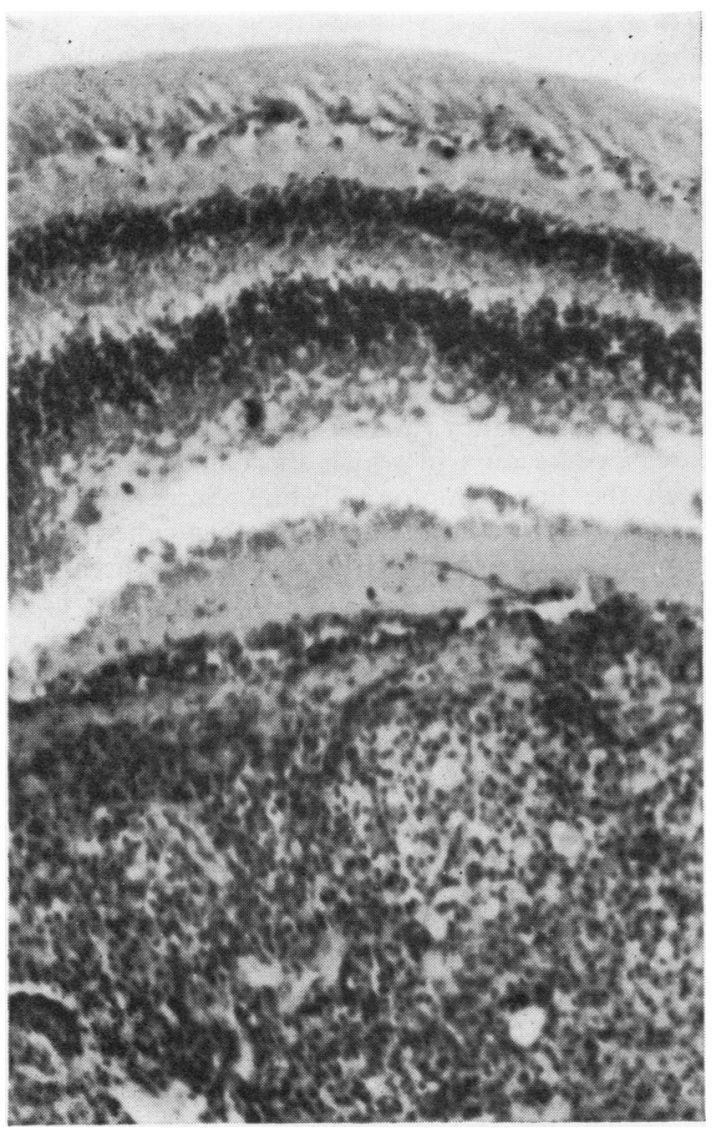

FIG. 1. Case 1. Transverse section of left globe showing sclera, retinal layers, and tumour. $H$. and $E . \times 63$.

sone, $0.5 \mathrm{mg}$ three times a day orally, was then started but he continued to deteriorate and died in April 1970.

At necropsy, a squamous carcinoma, $3 \mathrm{~cm}$ in diameter, was found in the left lower lobe in addition to diffuse pulmonary fibrosis. There were numerous neoplastic deposits in the liver and in both cerebral hemispheres.

CASE 3 A 53-year-old housewife, who did not smoke, presented in March 1970 with a two-month history of disturbed vision in the right eye. Fundal examination showed a subhyaloid haemorrhage arising near the right optic disc (and an apparent choroidal lesion causing, but obscured by the haemorrhage). The left fundus was normal and no other abnormal signs were found. Five weeks later, as the haemorrhage cleared, a solid pigmented choroidal lesion with recent retinal haemorrhages was seen on the superotemporal side of the disc. The patient complained of loss of weight and bilateral ankle swelling. There was no finger

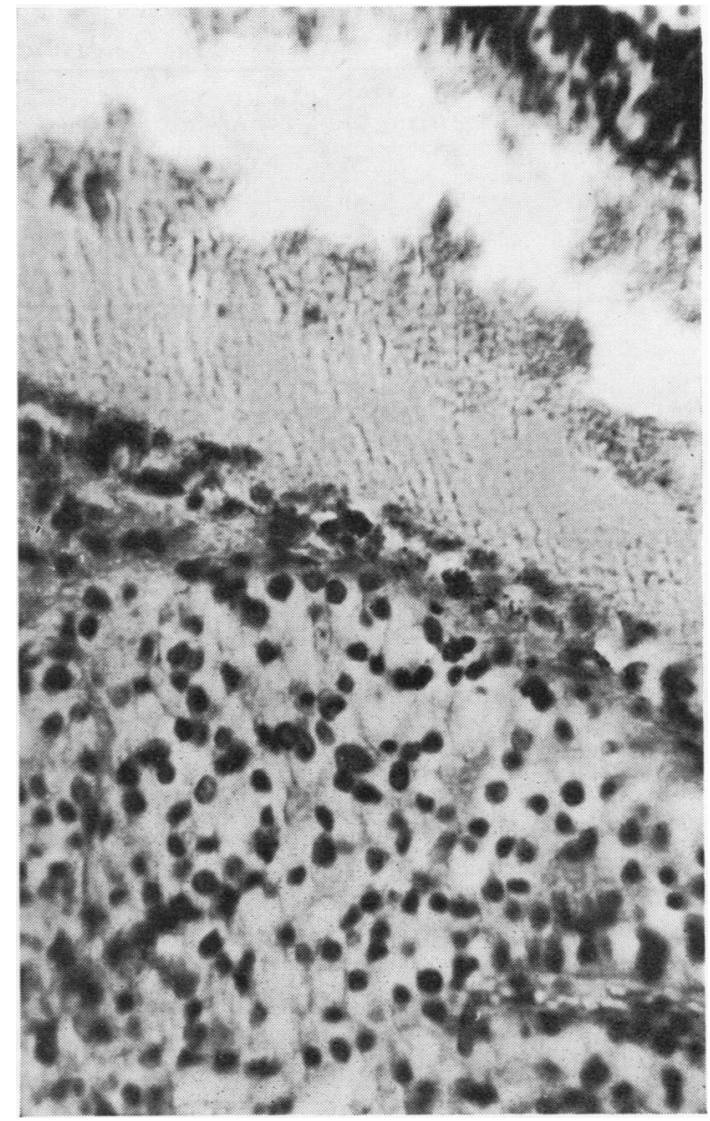

FIG. 2. Same as Fig. 1, showing clear cell type of secondary bronchial neoplasm. $H$. and $E . \times 150$.

clubbing and the lungs were clinically clear. A chest radiograph revealed a small round lesion at the left hilum with infiltration of the surrounding lung.

At bronchoscopy the left main bronchus was narrowed and rigid, and a biopsy showed a carcinoma simplex.

Treatment was begun with cyclophosphamide, 200 mg intravenously daily, and after 10 days she was given $150 \mathrm{mg}$ orally in divided doses. There was improvement in the retinal appearances.

The patient was admitted to the Liverpool Royal Infirmary in June because she had developed both a proximal myopathy and diabetes mellitus requiring insulin. The plasma potassium level was $1.2 \mathrm{mEq} / \mathrm{l}$. on admission and never rose above $3.1 \mathrm{mEq} / 1$. in spite of potassium replacement. A fasting plasma cortisol of $86 \mu \mathrm{g} / 100 \mathrm{ml}$ (normal 5-15 $\mu \mathrm{g} / 100 \mathrm{ml}$ ) supported the diagnosis of a bronchial carcinoma actively secreting an ACTH-like substance. She died in July 1970, five months after presenting with visual symptoms. 
T A B L E

CLINICAL DETAILS

\begin{tabular}{|c|c|c|c|c|c|c|c|c|}
\hline Patient & Age (yr) & Sex & Eye Affected & Onset & Histology & $\begin{array}{c}\text { Cerebral } \\
\text { Secondaries }\end{array}$ & Therapy & Interval to Death \\
\hline 1 & 45 & $\mathbf{M}$ & Left & Visual & Clear & Yes & Cyclophosphamide & 8 months \\
\hline 2 & 54 & $\mathbf{M}$ & Right & Visual & Squamous & Yes & Cyclophosphamide & 5 months \\
\hline 3 & 58 & $\mathbf{F}$ & Right & $\begin{array}{l}\text { Visual } \\
\text { loss }\end{array}$ & Simplex & No & Cyclophosphamide & 9 months \\
\hline
\end{tabular}

At necropsy there was a large primary neoplasm arising from the left upper lobe bronchus with secondary deposits in the hilar glands and in the right middle lobe. There were multiple neoplastic deposits in the pericardium and liver, but the brain showed no gross abnormality. The cut surface of the right eye revealed a nodular grey tumour deposit adjacent to the optic disc with a secondary retinal detachment. Both adrenal glands showed pronounced uniform hyperplasia and together weighed $30 \mathrm{~g}$ (normal less than $15 \mathrm{~g}$ ).

\section{DISCUSSION}

In a review of 1,550 patients, Greer (1954) found the ratio of primary to secondary ocular tumours about $40: 1$. The rarity of ocular metastases is explained by the fact that the ophthalmic artery leaves the carotid artery at right angles so that malignant emboli tend to pass straight on and lodge in the brain or meninges (Duke-Elder and Perkins, 1966).

The female breast is the most common site of a primary tumour metastasizing to the eye (Greer, 1954), but other primary sources include the stomach, thyroid, liver, and lung. It had been estimated that only 10 to $15 \%$ of ocular secondary deposits arose from the lung (Giri, 1939), but, now that bronchial carcinoma is more common, more cases may be seen with a higher incidence in males. Moreover, Greear (1950) points out that a metastatic tumour in the uveal tract is easily overlooked when it is a minor feature in a patient with generalized carcinomatosis.

When both eyes are affected, this tends to be sequential rather than simultaneous (Nover and Schmidt, 1954), but the left eye is more commonly involved than the right. The anatomical explanation is that tumour emboli are more likely to pass from the heart into the left common carotid than the right, just as cerebral embolism is more often left-sided. Two of our three patients, however, had right-sided lesions (Table).

Although it is usual for ocular metastases to occur late in the disease process in a patient with known malignancy, Wilder (1946) drew attention $\tilde{N}$ to cases like ours in which the ocular lesion had been the first symptom (Table). Sometimes, the histology of the enucleated orbit has called attention to an unsuspected primary in the breast or lung. Haft and Worken (1954) described a case, $\overrightarrow{\vec{c}}$ similar to our case 2 , in which the secondary deposit simulated a primary ocular tumour.

Common presenting symptoms include disturbed $\vec{\theta}$ vision of sudden onset and periorbital pain. A central scotoma is frequently found and fundal examination is likely to reveal a pale grey solid looking lesion in the choroid with haemorrhages, retinal detachment, and sometimes a secondary glaucoma. Most often the lesion lies in the pos- $\stackrel{\mathbb{D}}{2}$ terior choroid on the temporal side near to the $\overrightarrow{\vec{O}}$ macula where the short ciliary arteries are most numerous.

Duke-Elder and Perkins (1966) and Reese (1963) have both drawn attention to the relative frequency of ocular metastases from bronchial carcinoid, but in our cases a clear cell, a squamous cell, and a simplex type of carcinoma were found.

Since ozular metastases indicate that cancer emboli have traversed the carotid artery, they will of often be associated with similar lesions in the brain or meninges. It is not surprising, therefore, 을 that neurological features due to intracranial $>$ metastases occurred in two of our cases (1 and 2). 을

For diagnostic reasons, enucleation of the eye $\bar{N}$ may be necessary and this may relieve pain (case $O$ 2). However, these lesions are often radiosensitive, $\stackrel{\sim}{\sim}$ irrespective of the primary tumour type (Cordes, $\underset{\omega}{N}$ 1944), and irradiation can restore vision as well as relieve pain. In some cases improvement can also 0 be achieved by cytotoxic agents such as cyclo- $\frac{\mathbb{D}}{\mathbb{D}}$ phosphamide (case 1). The prognosis is that of a $\stackrel{\mathscr{\infty}}{+}$ patient with carcinomatosis, and death usually 0 ensues within nine months.

We wish to thank Mr. E. Cook and Mr. S. I. David-

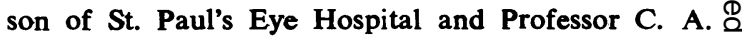
Clarke of the Liverpool Royal Infirmary for permis- $\bar{O}$ sion to study their patients; Mr. L. J. Temple, who performed the bronchoscopies; and Dr. C. M. Ogilvie 
for permission to study case 2 and for helpful advice and criticism in the preparation of this paper. We should also like to thank Dr. F. Whitwell who prepared the photomicrographs.

\section{REFERENCES}

Cordes, F. C. (1944). Bilateral metastatic carcinoma of the choroid with X-ray therapy to one eye. Amer.J. Ophthal., 27, 1355.

Duke-Elder, S., and Perkins, E. S. (1966). System of Ophthalmology. Vol. 9, p. 917. Kimpton, London.

Fishof, F. E. (1960). Bronchogenic carcinoma with metastasis to aphakic eye. Amer. J. Ophthal., 49, 96.

Giri, D. V. (1939). Metastatic carcinoma of the choroid secondary to mammary carcinoma in a man. Schweiz. med. Wschr., 20, 1069.

Greear, J. N. Jr. (1950). Metastatic carcinoma of the eye. Amer. J. Ophthal., 33, 1015.

Greer, C. H. (1954). Choroidal carcinoma metastatic from the male breast. Brit. J. Ophthal., 38, 312.

Haft, A. S., and Worken, B. (1954). Metastatic carcinoma of the choroid (bronchogenic) simulating primary tumor of the eye. Arch Ophthal. (Clin.), 51, 445.
Koenig, R. P., Johnson, D. L., and Monahan, R. H. (1963). Bronchogenic carcinoma with metastases to the retina. Amer. J. Ophthal., 56, 827.

Nover, A., and Schmidt, H. (1954). Uber Doppelseitige Carcinom-Metastasen in der Augenhöhle und dem Auge. Ophthalmologica. (Basel), 127, 14.

De Ocampo, G., and Espiritu, R. (1959). Metastatic bronchogenic carcinoma to the choroid. Phillip. J. Surg., 14, 272.

Perls, M. (1872). Beiträge zur Geschwulstlehre. Virchows Arch. path. Anat., 56, 437.

Reese, A. B. (1963). Tumors of the Eye, 2nd ed., p. 516. Hoeber, New York.

Sakula, A. (1968). Metastasis of bronchial carcinoma to the eye. Brit. J. Dis. Chest, 62, 32.

Thomas, C., Algan, B., and Reny, A. (1964). Métastase à l'uvée antérieure d'un cancer bronchique. Bull. Soc. Ophthal. Fr., p. 938.

Wilder, H. C. (1946). Intra-ocular tumors in soldiers, World War II. Milit. Surg., 99, 459.

Wright, J. C., and Meger, G. E. (1962). Bronchogenic carcinoma, metastatic to the choroid. Amer. J. Ophthal., 53, 1003. 